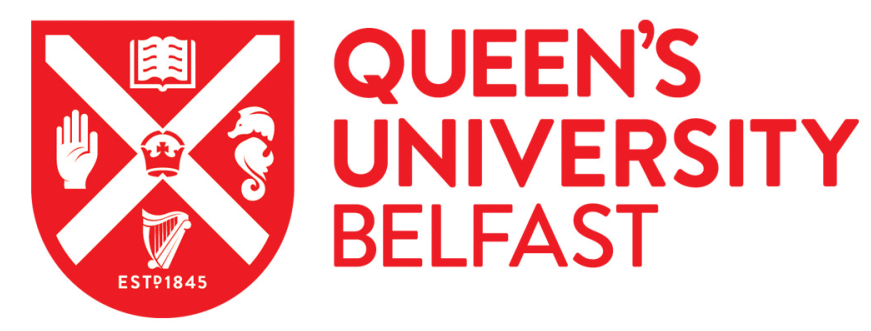

\title{
Re-engineering justice? Robot judges, computerised courts and (semi) automated legal decision-making
}

Morison, J., \& Harkens, A. (2019). Re-engineering justice? Robot judges, computerised courts and (semi) automated legal decision-making. Legal Studies, 39(4), 618-635. https://doi.org/10.1017/lst.2019.5

\section{Published in:}

Legal Studies

Document Version:

Peer reviewed version

Queen's University Belfast - Research Portal:

Link to publication record in Queen's University Belfast Research Portal

Publisher rights

(C) 2019 The Society of Legal Scholars.

This work is made available online in accordance with the publisher's policies. Please refer to any applicable terms of use of the publisher.

\section{General rights}

Copyright for the publications made accessible via the Queen's University Belfast Research Portal is retained by the author(s) and / or other copyright owners and it is a condition of accessing these publications that users recognise and abide by the legal requirements associated with these rights.

Take down policy

The Research Portal is Queen's institutional repository that provides access to Queen's research output. Every effort has been made to ensure that content in the Research Portal does not infringe any person's rights, or applicable UK laws. If you discover content in the Research Portal that you believe breaches copyright or violates any law, please contact openaccess@qub.ac.uk. 


\title{
Algorithmic Justice: Dispute Resolution and the Robot Judge?
}

\author{
John Morison and Adam Harkens \\ School of Law, QUB
}

\section{Introduction}

The exponential growth of power in computing technology, combined with the development of big data, the internet of things and machine learning is transforming our world (Kelly and Hamm 2014; Greenfield 2017). A burgeoning robotics industry is already making many humans redundant from a wide range of occupations, extending beyond those that are routine and repetitive and into a range of white collar jobs (Brynjolfsson and McAfee 2014). While occupations that involve judgment and human interaction are likely to be among the last to be taken over by machines, a significant study of the impact of technology on 702 occupations found lawyers and judges to be more or less at the mid point of jobs likely to be replaced by technology (Frey and Osbourne 2013). Software that can scan documents for key words and phrases has already transformed the role of paralegals and legal assistants. ${ }^{1}$ It is certainly possible that the role of lawyers might be augmented by machines but could they, or even judges, be replaced by robots? In this contribution we consider the possibility of this and examine some of the issues that are raised.

A focus on dispute resolution - rather than more formal hearings or trials perhaps affords the strongest opportunity for the case to be made for technology. However we should declare an initial and strong skepticism that the essentially social nature of law can be reproduced by machines, no matter how sophisticated. Nevertheless we will note the evolution of "Alternative Dispute Resolution" (ADR) into "Online Dispute Resolution"(ODR), and review briefly how the component tasks of mediation might be thought to lend themselves to technological enhancement. We will be particularly alive to the issue of whether any of this technology has the potential to amount to a new system of dispute resolution as opposed to simply being a tool to augment existing processes. We will speculate as to whether the sort of patterns that might be gathered from big data and sorted by machine learning algorithms could provide the basis of a new approach, and what this might mean.

\section{ADR to ODR - The Promise of Digital Justice}

There is no doubting both the policy push for technology and the roll-out of various pioneering examples within dispute resolution in the UK and beyond. ${ }^{2}$

\footnotetext{
${ }^{1}$ See for example The In-House Counsel's LegalTech Buyer's Guide 2017 (available at https://www.lawgeex.com/buyersguide/ ) which list over 100 "technology solutions" in what has been estimated to be a $\$ 16$ billon market in the USA alone.

2 For example, for the UK see: Lord Woolf, Access to Justice (1995, 1996), Lord Justice Jackson, Review of Civil Litigation Costs (2010), Hazel Genn, Judging Civil Justice (2009), and Hodge, Jones \& Allen, Innovation in Law Report 2014 (2014), Online Dispute Resolution for Low Value Civil Claims (2015), and for a critical voice see Transform Justice's Briefing on
} 
As stated in the Ministry of Justice's Transforming our justice system report (2016, p.3), digitisation of proceedings is intended to play a major role in ensuring that the legal system of England and Wales provides "swift and certain justice", in a manner that "[saves] people time and money, and [shrinks] the impact of legal proceedings on their lives." Behind this goal is the belief that the current political culture of austerity lays the platform and provides the opportunity to transform and reconfigure how the courts and tribunal systems work in the UK (Marks, 2016; Donoghue 2017).

In a context where the number of disputes is rising in a way not matched by the capacity of the formal system to provide effective access to justice, the promise of information and communication technology (ICT) is irresistible. The features of economy, accessibility, reach, speed and enhanced information management are valuable in the context of providing low cost dispute resolution. Of course new technology does not only promise solutions it also multiplies the number of disputes and their complexity as online trading across jurisdictions, internet shopping and the internet-enabled gig or sharing economy provides occasion for increased dispute. Nevertheless as Katsh and Rabinovich-Einy $(2017$; 33-4) point out, some of the problem features of ICT - lack of face-to-face interaction, collection of all data, absence of privacy and reliance on the "intelligence" of the machine - can be beneficial in the context of ADR as where asynchronous communication allows time to consult and research, full data builds up a wider picture, decrease in privacy can assist in quality control and prevention strategies, and intelligence of the machine can enhance efficiency through automation of large numbers of small-scale disputes. Certainly there are many examples of simple and effective dispute resolution mechanisms utilising ICT (Wahab, Katsh and Rainey 2012; Civil Justice Council 2015; Duchateau et al 2016). Providers such as The Mediation Room (http://themediationroom.com/) and Benoam (http://www.benoam.co.il/) have developed online platforms to allow mediators and arbitrators to exchange documents and communicate online. Cybersettle and, more recently, TryToSettle.com, offer a blind bidding system where the parties to a dispute can attempt to find a match between offer and demand, while Smartsettle encourages parties to list their interests and assign them a value to allow a more complex spectrum of agreement to be attained. In Germany and France, the government funded system Online Schlichter is used as an online mediation service for Business-to-Consumer e-commerce and direct selling disputes (see https://www.online-schlichter.de/vorzuege-derschlichtung/online-schlichter-an-odr-body-for-online-trading). eBay's ODR system developed by SquareTrade is perhaps the most used format worldwide with more than sixty million disputes every year. Online forms are used initially to make claims and demands, and an online mediation with human mediators is available if no early resolution is made. (There is even an interesting crowdsourcing variation used by an eBay subsidiary in the Netherlands called Marketplaats which uses randomly selected volunteer jurors to adjudicate disputes.)

the Prisons and Courts Bill (2017). For the EU see: ADR Directive (Directive 2013/11/EU) and ODR Regulation (Regulation 524/2013) of 24th May 2013. For China see: Chinese judicial justice on the cloud: a future call or a Pandora's box? An analysis of the 'intelligent court system' of China (2016) 
While all of these examples are no doubt useful, the technology seems to act mainly as a tool to assist in dispute resolution rather than an autonomous system which can actually process, adjudicate or settle disputes independently. Katsh and Rabinovich-Einy (2017) identify three major phases in the development of ODR whereby services have moved from simply putting the various elements of the dispute resolution triad on-line, through systems which deploy software to support and assist resolution, to the current (or indeed next) generation where the emphasis is on algorithms and smart machines using and re-using data to inform and underwrite systems that prevent disputes, or find easy ways to resolve them. This introduces an important distinction. There are those ICT elements that contribute to dispute resolution in rather the same way as a complaints form, at the first level of evolution by simply making (a sometimes complex) account of the dispute available to be compiled and addressed by the parties online. At the next level not only is there software that may, for example, manage blind bids in an effort to reach settlement but also relative straightforward algorithms that may apply various rules in relation to multiple factors. For example, in the context of an online shopping forum such as Amazon, if the buyer is a frequent purchaser or Amazon Prime member, an infrequent returner of goods, or if the goods are of low value or the subject of many complaints, then a particular outcome - a refund or replacement or whatever - may be produced by the algorithm without the intervention of any costly human resources. This again is useful: it may improve the consumer experience and is certainly a more economically efficient business model than using human mediators in a telephone complaints department. However it is not really replicating the work of a court, or even necessarily a mediator.

At the third level data is collected in bulk quantities and examined and re-used by algorithms in a process of determining patterns. Again this may be valuable in ascertaining ways of avoiding disputes - keep the terms and conditions clear, provide a better description of the goods, offer a faster delivery service or whatever - but it does not amount to the sort of exercise in achieving third party agreement, with all the elements of discretion, appeal to authoritative determination or middle way arbitration that characterizes the classic triad of dispute resolution (Gulliver 1973; Shapiro 1986; Roberts and Palmer 2005). Algorithms here are being used as an aid or tool within a wider process. This is similar to the way in which algorithms are being used routinely, if not un-controversially, in the United States Justice system. For example, in relation to bail applications President Obama's Data-Driven Justice initiative commits 67 city, county, and state governments across the USA to using data-driven strategies to divert low-level offenders with mental illness out of the criminal justice system (White House 2016) while in terms of sentencing US Chief Justice Roberts created some controversy in an interview reported in the New York Times (Liptak 2017) which drew attention to a case in the Wisconsin Supreme Court dismissing an appeal against a sentence which was based on a prediction made by a private company's proprietary software (see also Cristin et al 2015). 
It is of course important to be careful to distinguish between the various elements of arbitration, negotiation, mediation and the various hybrid forms of ADR as well as straightforward adjudication (Roberts and Palmer 2005; Fuller 1970; Mustill 1989; Fuller and Winston 1978). However if we parse out the various elements of dispute resolution it can be seen that most ICT enhanced processes are some way off replicating the human umpire. A dispute will involve variations of the following steps: identifying the issues, establishing "facts" - with varying degrees of evidential formality, ascertaining the relevant legal framework, providing an opportunity for venting feelings, evaluating the parties' interests, disaggregating issues, establishing positions, exchanging information, suggesting options for resolution, setting out a time frame for actions, seeking agreement and creating binding resolutions. Routine civil disputes or consumer matters may sometimes be reducible to such steps. The high volume of cases in administrative tribunals too may capable of analysis into a number of steps and certainly the Transforming our Justice System (2016) report mentioned above contains a vision for tribunals to include online hearings, traditional in-person hearings, and a mixture of the two. It envisages a new, simpler, procedure occurring online where lay users can be guided through the system in areas such as social security and child support (Tomlinson 2017). It is certainly possible that in areas such as these various stage in dispute can be assisted by ICT and the wider process augmented but this does not really amount to machines doing the dispute resolution?

When we move to considering if the role of a court sensu stricto could be reproduced we find that there is, as Cranston points out, "an academic industry" considering what is involved here (Cranston 1986 n.2). In its various branches this involves considering the adjudication and law-making aspects of a court and covers issues such as the use of discretion in decision-making, resolving hard cases and factoring in the role of morality and policy arguments. Cranston also describes the strand of legal anthropological writing that focuses on disputes and their resolution, and the work which distinguishes courts from mediation or arbitration by concentrating on the application of doctrine and the use of legal method. There is also the approach that sees courts as part of a wider political process, reinforcing allocations of wealth and power, restating the rights, rules, entitlements and obligations underpinning society, and supervising markets. Courts too are part of the wider constitutional landscape. This may true not only in a general sense but as they operate in relation to individual cases. Summers (1974: 3) refers to "process values" within courts systems involving participatory governance, procedural rationality and humaneness. In a recent landmark decision about the costs of justice the UK Supreme Court affirmed that actual and effective access to justice, and the procedure that the courts and tribunals provide, is not merely a public service like any other but a key part of the rule of law and the fabric of rights (R (Unison) $v$ Lord Chancellor [2017] UKSC 51).

Of course we must distinguish clearly between minor civil disputes, major cases and those with complex law or facts. The various constituent elements or procedural requirements will vary in their formality as the stakes rise. In more serious criminal cases the system is perhaps at its most complex with 
strict rules of evidence and full opportunity to participate in the process. Indeed it is this element of participation in a decision that effects an individual - with all the rights that this engages - that is centrally characteristic to a formal legal dispute. In a series of cases considering the adequacy of government public consultation procedures the courts have looked at how different process elements drawn from court procedures - from a right to a hearing, to rights to know reasons for a decision, have time for consideration and response etc. - relate to fairness, and indeed to wider issues of democracy and dignity (Morison 2017). There is clearly much more to a court case than a simple dispute.

Our position here is however much simpler. We see the difficulty with reproducing the legal process by machines as arising from the essentially social nature of law. In the same way as the early pioneers of Artificial Intelligence (AI) took up law as a potentially fruitful area where they believed that they could model what they saw as straightforward "rules" into machine code, (Leith 1989) so there remains a view among many ICT enthusiasts today that law is about clear-cut rules applied to uncontroversial facts. ${ }^{3}$ This is of course not the case. The actual practice of law is a highly social activity occurring within the complex milieu of legal practice where "facts" are negotiated among the parties, who must of course agree about what they are disagreeing about, before entering into the complex social interactions of the courtroom. As one of us has argued in an empirical study drawing upon the legal realism of Jerome Frank there is a category of "legal information", wider than simply law and fact (Morison and Leith 1992; Leith and Morison (2005). This is socially produced and acted on by dynamic processes within the wider legal system which are complex and contingent on a social context in ways that it is difficult to imagine ICT capturing. This remains the case even with more specialist, upper court decisions where one might imagine that facts are more settled and the law more specialist (Morison 2012).

All this suggests that while technology may be very useful in some circumstances, providing an enhanced form of customer service, it is some distance from taking over the role of courts. However the well-known axiom of microprocessor development, enshrined as Moore's law suggesting that computing power doubles every 18 months, presents a picture where radical development is possible. As noted already, big data and machine learning are transforming the most unexpected areas of life. As Marshall McLuhan observed "when a new technology comes into a social milieu it cannot cease to permeate that milieu until every institution is saturated" (McLuhan 1964: 223). Why should lawyers and courts be different?

\section{Big Data and ODR}

In order for algorithms to entirely permeate the present socio-legal milieu, machine learning would need to reach the point whereby a judge, or at least some form of surrogate judging system, could be produced either semi or fully

\footnotetext{
${ }^{3}$ See, for example, the work of the International Association for Artificial Intelligence and Law at http://www.iaail.org (accessed 11 ${ }^{\text {th }}$ August 2017).
} 
autonomously using big data analytics. This immediately conjures images of a robot judge dispensing justice within an artificially intelligent court, although judgment would just as likely be provided in something as simple as a computer screen (as in many ODR technologies).

For example, the Traffic Penalty Tribunal (TPT) in England and Wales allows drivers to appeal tickets handed out by local authorities online. ${ }^{4}$ The idea behind this is that it follows what Shapiro $(1981$, p.1) refers to as the ideal prototype of courts, whereby an independent adjudicator applies the relevant law to the facts at hand, within adversarial proceedings, to produce a dichotomous decision that announces one party as being legally right, and one as legally wrong (without any need for legal representation in this case). Applicants must enter the relevant Penalty Charge Notice (PCN) number, then provide reasons for their appeal, before their case is evaluated by an adjudicator. The realities of how well this system fits such an analysis could be debated, but the crucial point is that it has allowed large numbers of relatively simple cases to be dealt with online, and has been deemed as a successful case of digitisation in the UK Courts by the judiciary (Briggs, 2016).

While tools like the TPT allow drivers to appeal tickets through an online platform, the actual process of judgment or resolution is still carried out by a human actor who, ideally, neutrally assesses the evidence and arguments at hand, and fulfills the various steps of a dispute laid out above. A system of algorithmic dispute resolution, or robot judgment, would require something much more than this. The independent adjudicators would no longer be "lawyers with a minimum of five years' legal experience", ${ }^{5}$ but sophisticated algorithms with machine learning capabilities, operating with a powerfully adaptive and "mindless agency" to produce both decisions and predictions (Hildebrandt, 2015). In such a situation, those five years of human experience could arguably be outstripped or rendered irrelevant by a robot judge, in much less time than it took a human to gather up.

To create a system like this would require a complete instrumentalisation of the social aspect of law, as discussed above, into something that could be technologically calculated and predicted. Here, it would be an algorithmic actor identifying the issues and legal framework, establishing "facts", evaluating the parties' interests, disaggregating issues, establishing positions, exchanging information, suggesting options for resolution, setting out a time frame for actions, seeking agreement and creating binding resolutions.

However, the current level of technological ability would suggest that such a situation is a long way off because reproducing the social aspect of law is no mean feat - not to mention the potential for judicial and political opposition, the threat from the powerful lobby that is the legal profession, and the dangers associated with opening up new opportunities for private sector technical developers who may come to dominate the market and unduly influence what should be a state function. For now at least, ICTs represent 'disruptive

\footnotetext{
${ }^{4}$ See: https://www.trafficpenaltytribunal.gov.uk/want-to-appeal/ (Accessed $4^{\text {th }}$ August 2017)

${ }^{5}$ The requirement for office stated at https://www.trafficpenaltytribunal.gov.uk/ouradjudicators/ (Accessed $4^{\text {th }}$ August 2017)
} 
technologies', in that they may disrupt current working patterns and flows, but they cannot produce a new kind of justice system. As such they remain tools for current legal actors to augment their actions in specific tasks and processes. Indeed, a report by the Online Dispute Resolution Advisory Group (2015) for the Courts and Tribunals Judiciary in the UK states that while they envision Al carrying out various tasks in the future, such as "legal diagnosis", facilitation of negotiation without direct human involvement, and acting as "intelligent assistants" for judges, at no point is it proposed these same judges be replaced - meaning the final binding resolutions and decisions remain in human hands. Or at least it is to be hoped that this human control is maintained. In choosing this terminology and distinction between tool/system though, we do not mean to downplay or underestimate attempts to move towards such a system, or the transformative potential of these technologies for the law. Rather, we find them useful as a jumping off point for analysis of the new legal situation that we now find ourselves in. With that in mind, these issues can now be unpacked and explored further below.

\section{The Possibility of an 'Intelligent Court'}

It is now commonplace to hear that we are living in the middle of a "data deluge", a "data tsunami", or in the era of "data-ism" (Puschmann and Burgess, 2014; Lohr, 2015). Through digital technologies, social media, and the Internet of Things, data collection is presently both ubiquitous and pervasive, as online activity increasingly becomes a necessity for participation in $21^{\text {st }}$ century society (Weber and Weber, 2010; Matzner, 2014). We leave data trails wherever we go by shopping, browsing the web and interacting with the internet of things. A process of "datafication" is occurring whereby the data collected on people becomes a legitimate way to access, understand and control people (Mayer-Schoeberger and Cukier 2013; Van Dijck 2014). Without delving too deeply, as one of us has argued in a separate study, this environment has mainly been generated by a combination of the nature of digital technologies themselves - where data is often a by-product of their main function, such as HTTP cookies - quasi-legal instruments such as privacy policies, and economic incentives to put data to use such as for targeted marketing (Harkens, 2017). In other words, data production has come to be expected and is 'normal'.

To make sense of this vast array of newly available information, it is sorted into big data sets. Big data refers to collections of massive data sets so complex in variety, that traditional forms of analysis are insufficient. Instead algorithms are applied to carry out "bottom-up" learning through data-mining processes. ${ }^{6}$ These datasets are designed to be "exhaustive in scope" and,

\footnotetext{
${ }^{6}$ We are using the term "algorithm" in this context to refer not only to a mathematical construct with "a finite, abstract, effective, compound control structure, imperatively given, accomplishing a given purpose under given provisions" (Hill 2015) but also to encompass a machine learning element, and the lay sense of the term which includes implementation of the mathematical construct into a technology, and an application of the technology configured for a particular task in a social context (Beer 2017).
} 
through the deployment of algorithms, unique and far-reaching insights can be generated (Kitchin, 2014; Hildebrandt and Koops, 2010). Correlations can be used to predictively construct profiles about specific users or behaviours that will then inform future actions. At its simplest, for example, recommendation platforms allow companies like Amazon or eBay to suggest products to customers that they "might like", based upon previous purchases or browsing history. Such techniques have been referred to by Antoinette Rouvroy (2012, p.143) as data-behaviourism, or new ways of "producing knowledge [about future events] without considering the subject's psychological motivations, speeches or narratives, but rather relying on data." But, what does this mean for the law and dispute resolution? Are there genuine prospects of building a legal system based upon this data, and what would this look like?

Much can be, and has been, researched and discussed about the accuracy of the analysis involved in big data, privacy and data protection implications, issues with security, and state surveillance (Bellanova, 2016; Schneier, 2015). Notwithstanding these crucial subjects, for the purposes of this contribution, we would like to focus on the role of the judge, and specifically whether judicial reasoning - or the activity of judging - can be replicated by an algorithm, operating with machine learning capabilities. (To be clear, this is again distinct from the role of lawyers and legal assistants, where as we observed above, algorithms are having a significant effect on employment and working practices. There, increasingly, algorithms are used to digitally manage caseloads, collect and analyse huge amounts of documents during litigation discovery, predict the timing and outcomes of cases and negotiations - in order to manage billing and resources effectively - and also facilitate the digital presentation of evidence (Ashley 2017; Mills, 2016; Marciano 2017). Some of this may help judges too, but it is distinct from judging.

Here we find that there has been an interesting research focus on outcome prediction as researchers attempt to determine in what direction a court might decide. This is of course particularly interesting here as it connects most directly with dispute resolution and judging. Currently there are two categories of development: predictive tools for profiling individual behaviour; and predictive tools for profiling the behaviour of specific courts as a whole (and incidentally judicial reasoning within a given court). For any advocate, algorithmic analysis can help answer questions on the behaviour of a specific judge based on patterns of previous decisions (e.g. how they react to specific requests, or how they tend to structure negotiation), or it can assist with opposing counsel's legal history. ${ }^{7}$ In addition, services such as Justice Toolbox can provides potential litigants in the U.S. with lists of available lawyers, sorted on win rate percentage and a personal quality review out of five stars. ${ }^{8}$

This first set of technologies seem merely to be an acceleration of what lawyers have always done during adversarial negotiations, by sizing up

\footnotetext{
${ }^{7}$ For a leading example, see LexMachina. Further Information available at: https://lexmachina.com/legal-analytics/

${ }^{8}$ More information available at: https://www.justicetoolbox.com/
} 
opponents and judicial personality (Morison and Leith, 1992). While the results of data analysis may suggest certain strategies - and humans tend to defer to this algorithmic logic - there is no requirement to do so because these tools hold no decision-making power (Lyon, 2014; Zarsky, 2016). Whereas the other category of outcome prediction comprises something different; it represents a step towards encouraging algorithms to 'think' like judges, and therefore to predict judicial reasoning using machine learning. As a matter of policy, if the behaviour of a specific court could be accurately and predictively modelled by an algorithm, this same technology could potentially be designed-in and take over judicial decision-making powers in light of rising caseload issues, and in the interests of "effective management" - as a primary goal of courts in general (Leith and Hoey, 1998). This would be particularly powerful if combined with the data deluge of wider society, and its insights on disputants and legal subjects. Arguments often suggested in favour of this include the 'neutrality' of algorithms (in that some believe they avoid decisions based on politics or personality), efficiency, and the "immediate operationality" of big data analysis (Rouvroy, 2012).

There are two prime examples of studies into the algorithmic prediction of court behavior. First there is the attempt by Aletras et al (2016) to predict decisions of the European Court of Human Rights (ECtHR), and secondly, there is work by Katz et al (2017) to predict decisions of the United States Supreme Court. The former's model predicted 584 decisions with an average of $79 \%$ accuracy (as high as $84 \%$ for violations of Article 6 of the European Convention on Human Rights), and the latter predicted 28,000 case outcomes with $70.2 \%$ accuracy, and 240,000 judicial votes with $71.9 \%$ accuracy. Both studies used the available databases of judgments for each court to construct their model, applying natural language processing and machine learning algorithms to text-based material. The sheer scale of cases involved demonstrates the significant computing power of big data that was previously unavailable with other forms of analysis. The study by Aletras et al, in particular, is useful because the algorithm used was significantly more accurate at predicting outcomes based on facts and procedure, than on the relevant law (and even better again when combined). Given that facts and procedure make up a large chunk of the social reality of a case, this is a significant development, particularly as such technology is only in its infancy. If accuracy levels were improved, the question could be asked: would be it more beneficial to have a 'neutral' and 'objective' algorithm decide these cases? Despite this, it should be noted that since the ECtHR is an appeals court, the facts were not in dispute at this stage. It would no doubt be interesting to see how an algorithm would perform at the level of a lower court.

For now though, as noted above, algorithms remain as intelligent assistants and tools. Were a machine learning algorithm, such as those employed by Aletras and Katz, to take over decision and rule making powers unsupervised, there is no guarantee that they would continue to follow the same patterns of prediction. In such a situation, the law could become increasingly uncertain and contestable, as algorithms developed new styles of reasoning, based on pattern recognition and language indecipherable by legal subjects and other 
actors (Wilson, 2017). ${ }^{9}$ Indeed this contestability is already becoming an issue with current technology, as shown by the example mentioned above of the Loomis case in Wisconsin highlighted by the US Chief Justice, mainly because the logic and reasoning of the proprietary software used in the sentencing process is unavailable to the applicant, or any legal actor involved. Since this application has been denied, the opacity created by such a technological 'black box' has therefore been deemed acceptable in parts of U.S. law (Pasquale, 2015). ${ }^{10}$

\section{'Datafication', surveillance and judgment: dystopian futures?}

Although now we seem some distance from robot judges or algorithmic justice it is perhaps interesting to peer into a future where we might find the continuing technological revolution offering us possibilities that are presently difficult to imagine.

For example, a radical version of the "datafication" process mentioned above, where almost all aspects of everyday life are transformed into quantified data and subject to monitoring and predictive analysis, provides the possibility of a wholly new system of surveillance and control. In this situation, individuals are profiled and their behaviours modelled independently of any active input from them, as they become data subjects abstracted from their physical or real-world setting (Rouvery and Berns 2013). These "data doubles" as they are termed by Hegarty and Ericson (2000, p. 613) are made up of pure information and they can be profiled, analysed and targeted for intervention. Indeed as Galič et al (2017) point out within their discussion of surveillance capitalism, these data doubles are more important than real bodies within this system where our data double, comprising a profile of our datafied component parts as determined by others, operates as a shadow self that stands in for our physical self and allows us to be subjected to predictive analysis, and therefore the control of an algorithmic governmentality. Machines are using algorithms to sort and manage the electronic traces that we leave behind us For Bauman and Lyon (2013) this has the result that many systems and processes are cut off from any consideration of morality or indeed human input. Data doubles are categorized in a process of "liquid surveillance" in ways that are seemingly more trustworthy than relying on a person's own account of themselves or any system involving human judgment.

Much of the thinking around this shadow world of data doubles who can be subject to seemingly neutral, machine-made inferences, has grown up in the context of either predicting consumer behaviour or developing systems of surveillance. However it is perhaps not too much of a stretch to imagine some sort of future online panopticon where our lives are lived out leaving digital

\footnotetext{
${ }^{9}$ See the following for more information on the project referenced. Facebook have developed "dialog agents" capable of producing novel language and negotiating techniques, unsupervised. https://code.facebook.com/posts/1686672014972296/deal-or-no-deal-trainingai-bots-to-negotiate/

${ }^{10}$ Case materials available at: http://www.scotusblog.com/case-files/cases/loomis-vwisconsin/
} 
traces that provide an undeniable and indelible record of our activities and actions, and can be subject to a surveillance and a machine generated "judgment" on our conduct. While this may remain the stuff of science fiction for now it does seem to appear as a logical terminus for some of approaches to surveillance that are developing.

\section{Conclusions}

There is much about technology that is destabilising of existing ways of living and it should be no surprise that even the operation of law in the courts is challenged by a technology that revolutionizes how we handle information. As Susskind has predicted "online courts and ODR will prove to be a disruptive technology that fundamentally challenges the work of traditional litigators and of judges. In the long run I expect them to become the dominant way to resolve all but the most complex and high-value disputes" (2017 p. 121). We share this prediction in part, especially around settlement systems and dispute avoidance mechanisms: judges will increasingly adopt a "managerial stance" which will expand to encapsulate the umpiring of algorithmic functions in courts. However we maintain reservations about some elements of technology in the context of judging. In particular we feel it is important to resist the wilder claims about the coupling of the analytical capabilities of algorithms to the data deluge that we live in, and relying on machines to infer motivations and narratives through analysis of data patterns and correlations. It is perhaps heartening that the General Data Protection Regulation, which becomes effective in 2018 across the European Union, includes a right, subject to some exceptions, "not to be subject to a decision based solely on automated processing, including profiling, which produces legal effects". ${ }^{11}$ Based on the guidelines of the Article 29 Working Party (2017, p.8-9), a general prohibition will exist under the GDPR on decisions "based solely on automated processing", or in other words, "with no human involvement". Despite early worries that this wording opened a loophole whereby any nominal involvement of a human would be sufficient, as identified by Edwards and Veale (2017), the Article 29 Working Party (2017, p.9) have confirmed that 'meaningful involvement' beyond a 'token gesture' is required. In other words, the human in question must have the authority and competence to change the decision, meaning that it can be changed, at least hypothetically. Law, perhaps above all forms of social interaction, must remain a site for struggle for essentially human values. As Golder and Fitzpatrick (2009 p.79) argue, although the law is "inherently amenable to appropriation and instrumentalisation" by the logics of external powers (such as algorithmic prediction), law does maintain a social element that allows for resistance and contestation. The effect of this is that it is unlikely that we will ever see it converted into an automated algorithmic system.

\footnotetext{
${ }^{11}$ See Article 22(1) of European Parliament (2016) Regulation (EU 2016/ on the protection of natural persons with regard to the processing of personal data and on the free movement of such data, and repealing Directive 95/46/EC (General Data Protection Regulation) available at http://data.consilium.europa.eu/doc/document/ST-5419-2016-INIT/en/pdf accessed 14th August 2017.
} 


\section{References}

Article 29 Data Protection Working Party (2017) Guidelines on Automated individual decision - making and Profiling for the purposes of Regulation 2016/679. Available at:

ec.europa.eu/newsroom/document.cfm?doc_id=47742 (Accessed 09/01/2017)

Aletras, N., Tsarapatsanis, D., Preotiuc-Oietro, D. and Lampos, V. (2016) 'Predicting judicial decisions of the European Court of Human Rights: a Natural Language Processing perspective', Peer J Computer Science , (), pp. [Online]. Available at: https://peeri.com/articles/cs-93/ (Accessed: 8th August 2017).

Ashley, K. (2017) Artificial Intelligence and Legal Analytics: New Tools for Law Practice in the Digitial Age, Cambridge: Cambrdige University Press.

Bauman, Z. \& Lyon, D. (2013). Liquid surveillance. Cambridge: Polity Press.

Beer, D., (2017) "The social power of algorithms", Information, Communication \& Society, Vol. 20, No. 1, pp.1-13

Bellanova, R. (2016) 'Digital, politics, and algorithms: Governing digital data through the lens of data protection', European Journal of Social Theory, DOI: 10.1177/1368431016679167: pp. 1-19.

Briggs, LJ (2016) Civil Courts Structure Revie : Judiciary of England and Wales.

Brynjolfsson, E and McAfee, A. (2014) The Second Machine Age: Work, Progress and Prosperity in a Time of Brilliant Technologies New York: Norton.

Christin, A, Rosenblat, A and Boyd, D. (2015) Courts and Predictive Algorithms Data Rights and Civil Rights: A New Era of Policing and Justice (available at http://www.datacivilrights.org/pubs/20151027/Courts and Predictive Algorithms.pdf accessed 1st August 2017.

Civil Justice Council (2015) Online Dispute Advisory Group, Online Dispute Resolution for Law Value Civil Claims (available at https://www.judiciary.gov.uk/wp-content/uploads/2015/02/Online-DisputeResolution-Final-Web-Version1.pdf (accessed 31st July 2017).

Cranston, R (1986) “What do Courts Do?” 5 Civil Justice Quarterly 123.

Donoghue, J (2017) "The Rise of Digital Justice: Courtroom Technology, Public Participation and Access to Justice”, 80(6) Modern Law Review, 9951025

Duchateau, M. Fikkers S, Lane, L and van Schagen, E (eds) (2016) Evolution in Dispute Resolution: From Adjudication to ADR? The Hague: Eleven 
Publishing.

Edwards, L. and Veale, M. (2018) 'Slave to the algorithm? Why a 'right to an explanation' is probably not the remedy you are looking for', Duke Law \& Technology Review [Forthcoming] Available at:

https://papers.ssrn.com/sol3/papers.cfm?abstract_id=2972855 (Accessed: 29/12/2017).

Frey, CB and Osbourne, M. (2013) The Future of Employment: How Susceptible are jobs to Computerisation?

(http://www.oxfordmartin.ox.ac.uk/downloads/academic/The Future of Empl oyment.pdf (accessed 31st July 2017)

Fuller, L. (1970) "Mediation - its Forms and Functions" 44 Southern California Law Review 305.

Fuller, L and Winston, K (1978) "The Forms and Limits of Adjudication" 92 Harvard Law Review 2, 353.

Galič, M., Timan, T., and Koops, B., (2017) "Bentham, Deleuze and Beyond: An Overview of Surveillance Theories from the Panopticon to Participation", Philosophy \& Technology, Vol. 30, No. 9, pp.9-37.

Golder, B and Fitzpatrick. P. Foucault's Law, Abingdon Routledge.

Greenfield, Adam, (2017) Radical Technologies: The Design of Everyday Life London: Verso.

Gulliver, P.H. (1973) "Negotiations as a Mode of Dispute Settlement:

Towards a General Model”, Law \& Society Review, Vol. 7, No. 4 pp. 667-692

Harkens, A. (2017) [Forthcoming] "The ghost in the legal machine: Algorithmic governmentality, economy, and the practice of law", Journal of Information, Communication and Ethics in Society.

Haggerty, K.D., \& Ericson, R. (2000). "The Surveillant Assemblage”. British Journal of Sociology, 51(4), 605-622

Hildebrandt, M. (2015) Smart Technologies and the End(s) of Law, Cheltenham, Edward Elgar.

Hildebrandt, M. and Koops B.J. (2010) "The challenges of ambient Law and legal protection in the profiling era", Modern Law Review, 73(3), pp. 428-460.

Hill, R.K. (2015) "What an algorithm is". Philosophy \& Technology 29(1): 3559.

Katz DM, Bommarito MJ II, Blackman J (2017) A general approach for predicting the behavior of the Supreme Court of the United States. PLoS ONE 12(4). 
Kelly, J and Hamm S. (2014) Smart Machines: IBM's Watson and the Era of Cognitive Computing, New York: Columbia University Press.

Kitchin, R. (2014) The Data Revolution: Big Data, Open Data, Data Infrastructures \& Their Consequences, London, Sage Publications.

Leith, P. (1987) Formalism in Al and Computer Science London: Wiley.

Leith, P. and Hoey, A. (1998) The computerised lawyer: A guide to the use of computers in the legal profession, 2nd edn., London: Springer

Leith, P and Morison J (2005) "Can Jurisprudence Without Empiricism Ever be a Science?" in S. Coyle and G. Pavlakos eds. Jurisprudence or Legal Science? Oxford: Hart Publishing Pp. 147-168.

Liptak, A (2017) "Sent to Prison by a Software Program's Secret Algorithm" New York times $1^{\text {st }}$ May 2017.

Lohr, S. (2015) Data-ism: Inside the Big Data Revolution, London, Oneworld Publications.

Lyon, D. (2014) "Surveillance, Snowden, and big data: Capacities, consequences, critique", Big Data \& Society, Jul 2014 1(2) [Online]. Available at: http://bds.sagepub.com/content/1/2/2053951714541861 (Accessed: 8th August 2017).

Marciano, J (2017) "Automating the law: A Landscape of Legal A.I. Solutions", Topbots (available at http://www.topbots.com/automating-the-law-alandscape-of-legal-a-i-solutions/\#http://www.topbots.com/automating-the-lawa-landscape-of-legal-a-i-solutions/ accessed $9^{\text {th }}$ August 2017).

Marks, A. (2016) What is a Court?, A report by JUSTICE.

Matzner, T. (2014) "Why privacy is not enough privacy in the context of "ubiquitous computing" and "big data"”, Journal of Information, Communication and Ethics in Society, 12(2), pp. 93-106.

Mayer-Schoenberger, V., and Cukier, K., (2013) Big Data: A Revolution That Will Transform How We Live, Work, and Think, London: John Murray Publishers

McLuhan, M. (1964) Understanding Media: The Extension of Man New York: McGraw Hill.

Mills, M. (2016) Artificial intelligence in law: The state of play in 2016: Thomson Reuters.

Ministry of Justice (2016) Transforming our justice system: Summary of Reforms and consultation 
Morison, J and Leith P (1992) The Barrister's World and the Nature of Law Buckingham: Open University Press.

Morison, J (2012) "What Makes An Important Case? An Agenda for Research" 12 Legal Information Management, 4, 251-261.

Morison, J. (2017) "Citizen Participation: A Critical Look at the Democratic Adequacy of Government Consultations", Oxford Journal of Legal Studies, pp. $1-24$.

Mustill, Lord (1989) 'Arbitration: History and Background', 6 Journal of International Arbitration, 43.

Online Dispute Resolution Advisory Group (2015) Online dispute resolution for low value civil claims

Pasquale, F. (2015) The black box society: The secret algorithms That control money and information, Cambridge: Harvard University Press.

Puschmann, C. and Burgess, J. (2014) 'Metaphors of Big Data', International Journal of Communication, 8, pp. 1690-1709.

Roberts, S. and Palmer, M. (2005), Disputes Processes: ADR and the Primary Forms of Decision-Making $2^{\text {nd }}$ Edition Cambridge: Cambridge University Press.

Rouvroy, A. and Berns, T. (2013) "Algorithmic Governmentality and Prospects of Emancipation”, Réseaux, Vol. 1, No. 177, 2013, pp.163-196.

Rouvroy, A. (2012) "The end(s) of critique: data-behaviourism vs. dueprocess", in Hildebrandt, M. and De Vries, E. (ed.) Privacy, Due process and the Computational Turn. Philosophers of Law Meet Philosophers of Technology. Abingdon: Routledge, pp. 143.

Schneier, B. (2015) Data and Goliath: The Hidden Battles to Collect Your Data and Control Your World, W. W. Norton, New York.

Shapiro, M. (1986) Courts: A Comparative and Political Analysis Chicago: University of Chicago Press.

R. Summers, (1974) "Evaluating and Improving Legal Processes - A Plea for Process Values" 60 Cornell Law Review 1.

Susskind, R. (2017) Tomorrow's Lawyers $2^{\text {nd }}$ Edition. Oxford: Oxford University Press

Tomlinson, J (2017) 'The Policy and Politics of Building Tribunals for a Digital Age: How 'Design Thinking' Is Shaping the Future of the Public Law System', U.K. Const. L. Blog (21st Jul 2017) (available at https://ukconstitutionallaw.org/ accessed $10^{\text {th }}$ August 2017). 
Transform Justice (2017) Transform Justice briefing on the Prisons and Courts Bill.

van Dijck, J. (2014) "Datafication, dataism and dataveillance: Big Data between scientific paradigm and ideology", Surveillance \& Society, Vol. 12, No. 2, pp.197-208.

Wahab, M., Katsh E. and Rainey, D. (eds.) (2011) Online Dispute Resolution: Theory and Practice: A Treatise on Technology and Dispute Resolution The Hague: Eleven Publishing

Weber, R.H. and Weber, R. (2010) Internet of Things: Legal perspectives, Berlin: Springer

Wilson, M. (2017) Al is inventing languages humans can't understand. Should we stop it?, Available at: $h$ ttps://www.fastcodesign.com/90132632/ai-isinventing-its-own-perfect-languages-should-we-let-it (Accessed: 8th August 2017).

White House (2016) Fact Sheet: Launching the Data-Driven Justice Initiative: Disrupting the Cycle of Incarceration, available at https://obamawhitehouse.archives.gov/the-press-office/2016/06/30/fact-sheetlaunching-data-driven-justice-initiative-disrupting-cycle (accessed 1st August 2017).

Xu, A. (2016) 'Chinese judicial justice on the cloud: a future call or a Pandora's box? An analysis of the 'intelligent court system' of China, Information \& Communications Technology Law, 26(1), pp. 59-71.

Zarsky, T (2016) "The trouble with algorithmic decisions: An analytic road map to examine efficiency and fairness in automated and opaque decision making", Science, Technology and Human Values, 41(1), pp. 118-132. 